\title{
UČEŠĆE MEDICINSKE SESTRE SPECIJALISTE IZ OBLASTI JAVNOG ZDRAVLJA U PREVENCIJ PROFESIONALNIH BOLESTI I POVREDA NA RADU
}

\author{
Slavica Đorđević \\ ${ }^{1}$ Akademija strukovnih studija Beograd, Odsek Visoka zdravstvena škola
}

\begin{abstract}
APSTRAKT
Pitanja bezbednosti na radu i profesionalnih povreda i oboljenja predstavljaju ogroman problem, ne samo u našoj zemlji, već $i$ u svetu, a kako se globalni problemi povreda na radu i profesionalnih oboljenja u zdravstvenom sistemu povećavaju, sa njima se povećavaju i problemi smanjenja kvaliteta rada usled profesionalnog oboljenja ili povrede nastale na radu kao i negativan uticaj pojave profesionalnog oboljenja u životu svakog pojedinca.

Rad medicinskih sestara je vrlo složen i sveobuhvatan unutar zdravstvenog sistema i kao takav suočen je sa različitim rizicima i sa njima povezanim posledicama za zdravlje. Prema statistici ministarstva rada u SAD svake godine preko 35.000 medicinskih sestara i negovateljica doživi lokomotorne povrede zbog kojih moraju da otvore bolovanje.

To ukazuje da visokoobrazovane medicinske sestre moraju da imaju adekvatan nivo znanja o faktorima rizika, merama prevencije, kao $i$ bezbednosti na radu, tako i brige o sopstvenom zdravlju.

Prema istraživanjima Američkog udruženja medicinskih sestara (ANA), medicinske sestre koriste 30\% više bolovanja nego drugi zdravstveni radnici, što govori o učestaloj izloženosti neželjenim opasnostima, stresu, štetnim materijama i prekomernim fizičkim naporima.

Neusklađenost između zahteva vezanih za posao i okoline, odnosno nemogućnosti da se tim zahtevima udovolji dovode do profesionalnog stresa. Profesionalni stres je pojava kojoj su često izloženi zdravstveni radnici. Sindrom sagorevanja "burn out" rezultat je trajne ili učestale emocionalne opterećenosti nastale usled intenzivne brige za druge i pružanja pomoći drugima.

KLJUČNE REČI: profesionalna oboljenja, bezbednost na radu, povreda na radu, edukacija, rizično ponašanje, neželjeni događaji.
\end{abstract}

\begin{abstract}
Safety issues and occupational injuries and professional diseases or disorders - are enormous problems, not only in our country, but also in the world; and as the global problems of occupational injuries and professional diseases and disorders in the health providers system are increasing, with them increases the problems of decreasing quality of professional tasks due to occupational disease or injury occurred at work as well the negative impact of occupational disease occurrences in the life of every individual.

The work of nurses is very complex and comprehensive within the health system and as such is faced with various risks and related consequences for health. According to statistics Ministry of Labor in the United States each year more than 35,000 nurses and nurse experience locomotor injuries for which must open the sick leave.

This implies the need that the highly educated nurses must have an adequate level of knowledge about all risk factors, prevention measures and safety and care about their own health.

According to the research of the American Nurses Association (ANA), nurses use 30\% more sick leave than other health care workers, according to the incidence of exposure to unwanted risk, stress, harmful substances and excessive physical effort. The mismatch between the requirements related to the job and the environment, or the inability to satisfy those demands lead to professional stress. Professional stress is a phenomenon which often exposed health care workers. burn out syndrome is the result of persistent or recurrent emotional burdens incurred due to the intense concern for others and help others.
\end{abstract}

KEY WORDS: occupational diseases, safety at work, injuries at work, education, risky behavior, unwanted events.

UVOD:

Rad medicinskih sestara je vrlo složen i sveobuhvatan unutar zdravstvenog sistema i kao takav suočen je sa različitim rizicima i sa njima povezanim posledicama za zdravlje. Osim adekvatnog nivoa znanja, neophodno je uticati na stavove medicinskih sestara, promenu njihovog ponašanja kako bi se to primenilo u praksi, profesionalno i lično. Kako je stanje zdravlja značajno za zdravstvene radnike, ne samo sa profesionalnog već i ličnog aspekta, mnogi svoja znanja iz ove oblasti inoviraju ne samo putem formalnog obrazovanja, već i primenom neformalnih oblika obrazovanja. Ova studija sagledava znanja i stavove medicinskih sestara o povredama na radu i profesionalnim oboljenjima.

Pitanja bezbednosti na radu i profesionalnih povreda i oboljenja predstavljaju ogromne probleme, ne samo u našoj zemlji,već i u svetu, a kako se globalni problemi povreda na radu i profesionalnih oboljenja u zdravstvenom sistemu povećavaju, sa njima se povećavaju i problemi smanjenja kvaliteta rada usled profesionalnog oboljenja ili povrede nastale na radu, kao i negativan uticaj pojave profesionalnog oboljenja u životu svakog pojedinca.

\section{Korespondent:}

Slavica Đorđević, dipl.med.sestra

Akademija strukovnih studija Beograd

Odsek Visoka zdravstvena škola

e-mail: slavica.djordjevic30@gmail.com 


\section{CILJ RADA:}

Cilj rada je da se sagledaju razlike u nivoima znanja, stavovima i informisanosti zaposlenih medicinskih sestara ( srednjeg, višeg i visokog obrazovanja), kao i samoprocena o značaju primene zaštitnih mera i obezbeđivanja bezbednih uslova rada u radnoj sredini, kao i da se utvrdi nivo znanja i stavova o pitanjima bezbednosti i profesionalnim povredama i oboljenjima usled neželjenih događaja koji se dešavaju na radnom mestu.

\section{METOD RADA:}

Istarživanje je sprovedeno u domu zdravlja "Dr M.Ivković, Palilula”, toku decembra 2018. i januara 2019.godine. Korišćen je anketni upitnik sa 20 pitanja zatvorenog tipa. Ukupno je obuhvaćeno 64 ispitanika, medicinskih sestara-tehničara (MS) koje su raspoređene na punktovima/ambulantama(intervencije i previjališta ) sa analizom mesta rada (centralna ambulanta ili punkt DZ), stručne spreme, radnog iskustva u službi, informisanosti o zdravstvenim rizicima na radnom mestu, stavovima o značaju prevencije povreda u vezi sa radom, kao i upoznatosti postojanja pisane procedure za primenu mera zaštite na radnom mestu. Anketnim upitnikom izvršena je samoprocena o postojanju stresa na random mestu, kao i da li imaju oboljenja vezana za posao i kolika je prisutno odustvovanja sa posla usled profesionalnih bolesti ili povrede $u$ poslednjih godinu dana.

\section{TEORIJSKI OKVIR:}

Međunarodna organizacija rada (ILO) je proglasila 28.april za Svetski dan bezbednosti i zdravlja na radu, sa ciljem da se doprinese smanjenju broja smrtnih ishoda, a u vezi sa radom.

Zakon o penzijskom i invalidskom osiguranju RS(1) povredu na radu definiše kao povredu osiguranika koja se dogodila u prostornoj, vremenskoj i uzročnoj povezanosti sa obavljanjem posla, a profesionalne bolesti definišu se kao određene bolesti nastale u toku rada, prouzrokovane dužim neposrednim uticajem procesa $\mathrm{i}$ uslova rada na radnim mestima, odnosno poslovima koje je zaposleni obavljao.

Kao što je definisano od strane SZO "zdravlje na radu se bavi svim aspektima zdravlja i bezbednosti na random mestu i ima snažan fokus na primarnoj prevenciji opasnosti", a sve u cilju obavljanja svakodnevnih radnih zadataka sa što manjim posledicama na zdravlje radnika.

Posebno važan segmen je prepoznavanje rizika, procena i analiza mogućnosti za nastanak povrede na radu, kao i način za unađređenje kako bi se rizik eliminisao. Ukoliko se ipak utvrdi postojanje rizika koji bi i pored upotrebe zaštitne opreme i sprovođenja mera zaštite mogli dovesti do rizika po zdravlje, to radon mesto smatraće se radnim mestom sa povećanim rizikom, što se mora definisati i aktom o proceni rizika u samoj zdravstvenoj ustanovi (2).

Veoma je važno da medicinske sestre imaju razvijenu svest o značaju postojanja znanja u pogledu poštovanja procedura lične zaštite, kao i ličnu odgovornost prema sopstvenom zdravlju, a to je moguće pravilnom i kontinuiranom primenom zaštitne opreme. Posebnu pažnju treaba posvetiti motivisanju zaposlenih da prijave neželjenu (akcedentnu) situaciju.

Prema podacima Uprave za bezbednost i zdravlje na radu u RS je u 2018.godini bilo 10.404 povrede na radu, 3 profesionalna oboljenja, a 7 smrtnih ishoda usled povreda na radu. Prema podacima od toga je 788 teških povreda, kao i teške povrede (pri dolasku, odlasku sa posla) 522, a 9.087 lakih povreda na radu. Najveći broj povreda na radu zabeležen je u delatnostima prerađivačke industrije (27,17\%), zdravstvene i socijalne zaštite (8,81\%), trgovine na veliko i trgovine na malo, popravke motornih vozila i motocikala $(8,68 \%)$ i saobraćaja i skladištenja $(8,18 \%)$ (3).

U svetu postoji trend da se promocija i unapređenje zdravlja uvrsti u programe koji su osmišljeni tako da se ohrabri i pomogne u izgradnji zdravog oblika ponašanja na radnom mestu.

Sprovođenje medijskih kampanja sa posebnim naglaskom na sestrinstvo kao profesiju je veoma značajan segment rada koji ima za cilj informisanje i podizanja svesti svih činilaca sistema o njihovim zakonskim obavezama i značaju unapređenja stanja u oblasti bezbednosti i zaštite na random mestu. Bilo bi dobro raditi na kontinuiranom usavršavanje nastavnog osoblja u cilju obezbeđenja kvaliteta nastave kako bi se oblasti bezbednosti i zdravlja na radu uvrstila u sve nastavne programe na svim nivoima obrazovanja medicinskih sestara (4).

\section{REZULTATI:}

Anketom je utvrđeno da su ispitanici najvećim delom 46,7\% sa radnim iskustvom od preko 20 godina staža, a $15,63 \%$ preko 50 godina starosti, što ukazuje na negativnu starosnu strukturu zaposlenih medicinskih sestra-tehničara (Tabela1).

\section{Tabela 1.}

\begin{tabular}{|c|c|c|c|}
\hline \multirow{3}{*}{ Pol ispitanika } & Muški & 2 & $3,12 \%$ \\
\hline & Ženski & 62 & $93,88 \%$ \\
\hline & Ukupno ispitanika & 64 & $100 \%$ \\
\hline \multirow{5}{*}{$\begin{array}{l}\text { Godine života } \\
\text { ispitivanog uzorka } \\
\text { (MS) }\end{array}$} & 20 do 29 godina starosti & 12 & $18,75 \%$ \\
\hline & 30 do 39 godina starosti & 18 & $28,12 \%$ \\
\hline & 40 do 49 godina starosti & 24 & $37,5 \%$ \\
\hline & Više od 50 godina starosti & 10 & $15,63 \%$ \\
\hline & Ukupno ispitanika & 64 & $100 \%$ \\
\hline \multirow{4}{*}{ Mesto rada } & Gradska ambulanta & 18 & $2,12 \%$ \\
\hline & Prigradska ambulanta & 42 & $65,63 \%$ \\
\hline & Seoska ambulanta & 4 & $6,25 \%$ \\
\hline & Ukupno ispitanika & 64 & $100 \%$ \\
\hline \multirow{4}{*}{ Stručna sprema } & Strukovna specijalizacija & 4 & $6,25 \%$ \\
\hline & Strukovne studije/viša škola & 18 & $28,12 \%$ \\
\hline & Srednja škola & 42 & $65,62 \%$ \\
\hline & Ukupno ispitanika & 64 & $100 \%$ \\
\hline \multirow{5}{*}{$\begin{array}{l}\text { Radno iskustvo } \\
\text { u službi }\end{array}$} & Do 5 godina radnog iskustva & 4 & $6,25 \%$ \\
\hline & 6 do 10 godina radnog iskustva & 8 & $12,5 \%$ \\
\hline & 11 do 20 godina radnog iskustva & 22 & $34,38 \%$ \\
\hline & Više od 20 godina radnog iskustva & 30 & $46,7 \%$ \\
\hline & Ukupno ispitanika & 64 & $100 \%$ \\
\hline
\end{tabular}

Uglavnom su dosta dobro informisani o zdravstvenim rizicima na radnom mestu 75\%, ali ipak postoji potreba za unapređenjem jer 15,63\% nije dovoljno informisano o zdravstevnim rizicima na radnom mestu (Tabela 2).

Jednoglasno dele stav o značaju prevencije povreda u vezi sa radom $100 \%$, većina $96,8 \%$ upoznati su sa postojanjem pisane procedure za primenu mera zaštite na radnom mestu. Većina 96,8\% primenjuju mere zaštite na radnom mestu. Najvećim delom $71,8 \%$ smatra da zaštitna sredstva postoje(ali nisu u dovoljnoj meri dostupna na radnom mestu), dok 21,87\% smatra da nisu dovoljno dostupna zaštitna sredstva što ukazuje da samo 6,45\% smatra da su sredstva za zaštitna dostupna u potpunosti (Tabela 2).

Stavovi o potrebama sprovođenja periodičnih zdravstvenih pregleda su podeljeni, tako da $53,12 \%$ smatra da periodični pregled treba da se sprovoditi na 6 meseci, a 46,88\% ispitanika smatra 


\section{Tabela 2.}

\begin{tabular}{|c|c|c|c|}
\hline \multirow{4}{*}{$\begin{array}{l}\text { Informisanost } 0 \\
\text { zdravstvenim } \\
\text { rizicima na } \\
\text { radnom mestu }\end{array}$} & U potpunosti informisan/a & 48 & $75 \%$ \\
\hline & Delimično informisan/a & 6 & $9,37 \%$ \\
\hline & Nedovoljno informisan/a & 10 & $15,63 \%$ \\
\hline & Ukupno informisan/a & 64 & $100 \%$ \\
\hline \multirow{4}{*}{$\begin{array}{l}\text { Stav o značaju } \\
\text { prevencije povreda } \\
\text { u vezi sa radom }\end{array}$} & Izuzetno značajno & 64 & $100 \%$ \\
\hline & Značajno & 0 & $0 \%$ \\
\hline & Nije od značaja & 0 & $0 \%$ \\
\hline & Ukupno ispitanika & 64 & $100 \%$ \\
\hline \multirow{4}{*}{$\begin{array}{l}\text { Upoznatost sa postojanjem } \\
\text { pisane procedure za } \\
\text { primenu mera zaštite na } \\
\text { radnom mestu }\end{array}$} & $\mathrm{Da}$, upoznata sam & 62 & $96,88 \%$ \\
\hline & Ne znam & 2 & $3,12 \%$ \\
\hline & Ne postoji & 0 & $0 \%$ \\
\hline & Ukupno ispitanika & 64 & $100 \%$ \\
\hline \multirow{4}{*}{$\begin{array}{l}\text { Redovnost primene } \\
\text { zaštitnih mera na } \\
\text { radnom mestu }\end{array}$} & Upotpunosti & 62 & $96,88 \%$ \\
\hline & U zavisnosti od situacije & 2 & $3,12 \%$ \\
\hline & Neredovno & 0 & $0 \%$ \\
\hline & Ukupno ispitanika & 64 & $100 \%$ \\
\hline \multirow{4}{*}{$\begin{array}{l}\text { Stav o dostupnosti } \\
\text { sredstava na } \\
\text { radnom mestu }\end{array}$} & Dostupna u potpunosti & 4 & $6,45 \%$ \\
\hline & Dostupna su, ali ne dovljno & 46 & $71,88 \%$ \\
\hline & Nisu dovoljno dostupna & 14 & $21,87 \%$ \\
\hline & Ukupno ispitanika & 64 & $100 \%$ \\
\hline
\end{tabular}

da je dovoljno jednom godišnje. Najveći broj ispitanika 59,38\% odgovorilo je da ne zna da li imaju oboljenje vezano za posao kojim se bave, dok je veliki broj njih $28.12 \%$ na osnovu samoprocene smatrao da postoje oboljenja koja imaju veze sa radom (Tabela 3 ).

Najveći deo ispitanika 68,75\% smatra da je njihov posao izuzetno stresan. Mali broj ispitanika 9,38\% je u poslednjih godinu dana odsustvovalo sa radnog mesta zbog profesionalne bolesti ili bolesti vezane sa radom (Tabela 3 ).

Najveći broj ispitanika $62,50 \%$ je u potpunosti upoznato sa procedurom prijave neželjenog (akcedentnog) događaja, ali $31,25 \%$ nije upoznato sa procedurom, kao i 6,25\% tvrdi da ne zna odgovor govori da postoji potreba za unapređenjem u ovom segment (Tabela 3).

Više od pola ispitanika $53,12 \%$ daje podatak da je doživelo neželjeni događaj i pored mera zaštite na radu. Posebno je značajno da i dalje trećina ispitanika 31,25 \% nikada ne prijavljuje neželjeni događaj (Tabela 3).

Najveći broj ispitanika $84,38 \%$ smatra da je najprikladniji način obuke zaposlenih za primenu zaštite na radu demonstracija mera uz postojanje pisane procedure o primeni, što se i u stručnoj

\section{ZAKLJUČAK}

Medicinske sestre kroz svoje obrazovanje dobijaju dovoljno informacija i stiču znanja o profesionalnim bolestima koje mogu da očekuju na radnom mestu. Istraživanje je pokazalo da ta znanja treba da se obnavljaju i nadograđuju, uz preporuku da to bude edukacija na samom radnom mestu, najbolje u vidu demonstracije bezbednosti na radu kao i prepoznavanja rizičnog ponašanja na radnom mestu.

Uloga strukovnih medicinskih sestara, posebno specijalista iz oblasti javnog zdravlja je da svoje znanje i iskustvo prenesu na kolege i da se poveća broj onih koji poštuju procedure u svakodnevnom radu.
Tabela 3.

\begin{tabular}{|c|c|c|c|c|}
\hline \multirow[t]{2}{*}{ Tvrdnja } & \multicolumn{4}{|c|}{ Odgovori } \\
\hline & $\mathrm{Da}$ & $\mathrm{Ne}$ & Ne znam & Ukupn \\
\hline \multirow{2}{*}{$\begin{array}{l}\text { Utvrđena oboljenja } \\
\text { u vezi sa radom }\end{array}$} & 18 & 8 & 38 & 64 \\
\hline & $28.12 \%$ & $12.50 \%$ & $59.38 \%$ & 100.00 \\
\hline \multirow{2}{*}{$\begin{array}{l}\text { Stav o prisustvu stresa } \\
\text { na radnom mestu }\end{array}$} & 44 & 20 & 0 & 64 \\
\hline & $68.75 \%$ & $1.25 \%$ & $0 \%$ & 100.00 \\
\hline \multirow{2}{*}{$\begin{array}{l}\text { Odsustovanje sa posla zbog bolesti/ } \\
\text { povrede na radu u poslednjih } \\
\text { godinu dana }\end{array}$} & 6 & 52 & 6 & 64 \\
\hline & $9.38 \%$ & $81.25 \%$ & $9.38 \%$ & 100.00 \\
\hline \multirow{2}{*}{$\begin{array}{l}\text { Inofmisanost sa procedurom } \\
\text { prijave neželjenog događaja } \\
\text { za zdravlje na random mestu }\end{array}$} & 40 & 24 & 0 & 64 \\
\hline & $62.50 \%$ & $31.25 \%$ & $6.25 \%$ & 100.00 \\
\hline \multirow{2}{*}{$\begin{array}{l}\text { Iskustvo (lično) rizičnog događaja } \\
\text { za zdravlje na random mestu }\end{array}$} & 34 & 24 & 6 & 64 \\
\hline & $53.12 \%$ & $37.50 \%$ & $9.38 \%$ & 100.00 \\
\hline \multirow{2}{*}{$\begin{array}{l}\text { Prijava neželjenog događaja } \\
\text { za zdravlje na radnom mestu }\end{array}$} & 40 & 20 & 4 & 64 \\
\hline & $62.50 \%$ & 12 & $6.25 \%$ & 100.00 \\
\hline \multirow{2}{*}{$\begin{array}{l}\text { Iskustvo u prihvatanju sugestija od } \\
\text { značaja za bezbednost i zdravlje } \\
\text { na radu od strane poslodavca }\end{array}$} & 18 & 30 & 16 & 64 \\
\hline & $28.12 \%$ & $46.88 \%$ & $25.00 \%$ & 100.00 \\
\hline \multirow{2}{*}{$\begin{array}{l}\text { Stav o najprikladnijem načinu obuke } \\
\text { za primenu mera zaštite na radu }\end{array}$} & 10 & 0 & 54 & 64 \\
\hline & $15.62 \%$ & $0 \%$ & $84.38 \%$ & 100.00 \\
\hline \multirow{2}{*}{$\begin{array}{l}\text { Stepen satisfakcije brigom za } \\
\text { zdravlje i bezbednost na radu od } \\
\text { strane poslodavca }\end{array}$} & 18 & 8 & 38 & 64 \\
\hline & $28.12 \%$ & $12.50 \%$ & $59.38 \%$ & 100.00 \\
\hline
\end{tabular}

literaturi smatra kao najbolji način obuke. Najveći broj ispitanika $65,6 \%$ zadovoljan je merama koje poslodavac preduzima za bezbednost i zaštitu na radu, što ukazuje na visok stepen brige poslodavca za zdravlje zaposlenih u navedenom slučaju (Tabela 3), ali i postojanje suprotnosti u iskazanim stavovima u pogledu postojanja zaštitne opreme.

Analizirajući rezultate studije "Znanje, stavovi i percepcije profesionalnih opasnosti i bezbednosnih praksi kod nigerijskih zdravstvenih radnika"(5) autori su došli do zaključka da je visok nivo znanja koji su pokazali ispitanici u suprotnosti sa praksom.

Upoređujući rezultate iz navedene studiju sa rezultatima koji su prikazani u ovom radu uočava se da je zajedničko to da bez obzira na znanje medicinskih sestara i postojanje zaštitne opreme i dalje se dešavaju neželjene (akcedentne) situacije u visokom procentu, a kod nas se u visokom procentu i ne prijavljuje.

Sagledavajući rezultate njihove samoprocene dolazi se do jasnih zaključaka da je neophodno da se i dalje radi na unapređenju u pogledu razvijanja svesti o odgovornom ponašanju prema sebi, ali razvijanja svesti kod poslodavca o potrebi za pojačanim merama zaštite i bezbednosti na radu.

Posebnu pažnju treba posvetiti razvijanju navike prijave akcedentne sistuacije, koja bi dovela do pravovremene aktivnosti i ublažavanja posledica nastalih nakon same povrede. Sve to će imati veliki pojedinačni značaj za zdravlje kako medicinskih sestara tako i ostalih zdravstvenih radnika.

\section{LITERATURA}

1. https://www.paragraf.rs/propisi/zakon_o_penzijskom_i_invalidskom_osiguranju.html

2. https://www.paragraf.rs/propisi/pravilnik_o_nacinu_i_postupku_procene_rizika_na_radnom_mestu_i_u_radnoj_okolini.html

3. https://www.minrzs.gov.rs/sr/dokumenti/izvestaji/uprava-za-bezbednost-i-zdravlje-na-radu/izvestaji-o-radu

4. http://www.batut.org.rs/

5. Knowledge, attitudes and perceptions of occupational hazards and safety practices in Nigerian healthcare workers"; https: //bmcresnotes.biomedcentral.com/articles/10.1186/s13104-016-1880-2; BMC Research Notes volume 9, Article number: 71 (2016) 